\title{
Basic Compatibility of Albugo candida in Arabidopsis thaliana and Brassica juncea Causes Broad-Spectrum Suppression of Innate Immunity
}

\author{
A. J. Cooper, ${ }^{1}$ A. O. Latunde-Dada, ${ }^{2}$ A. Woods-Tör, ${ }^{1}$ J. Lynn, ${ }^{1}$ J. A. Lucas, ${ }^{2}$ I. R. Crute, ${ }^{2}$ and \\ E. B. Holub ${ }^{1}$
}

${ }^{1}$ Warwick-HRI, University of Warwick, Wellesbourne, Warwickshire, CV35 9EF, U.K.; ${ }^{2}$ Rothamsted Research, Harpenden, Hertfordshire, AL5 2JQ, U.K.

Submitted 4 December 2007. Accepted 28 February 2008.

\begin{abstract}
A biotrophic parasite often depends on an intrinsic ability to suppress host defenses in a manner that will enable it to infect and successfully colonize a susceptible host. If the suppressed defenses otherwise would have been effective against alternative pathogens, it follows that primary infection by the "suppressive" biotroph potentially could enhance susceptibility of the host to secondary infection by avirulent pathogens. This phenomenon previously has been attributed to true fungi such as rust (basidiomycete) and powdery mildew (ascomycete) pathogens. In our study, we observed broad-spectrum suppression of host defense by the oomycete Albugo candida (white blister rust) in the wild crucifer Arabidopsis thaliana and a domesticated relative, Brassica juncea. A. candida subsp. arabidopsis suppressed the "runaway cell death" phenotype of the lesion mimic mutant lsd1 in Arabidopsis thaliana in a sustained manner even after subsequent inoculation with avirulent Hyaloperonospora arabidopsis (Arabidopsis thaliana downy mildew). In sequential inoculation experiments, we show that preinfection by virulent Albugo candida can suppress disease resistance in cotyledons to several downy mildew pathogens, including contrasting examples of genotype resistance to $H$. arabidopsis in Arabidopsis thaliana that differ in the $\mathbf{R}$ protein and modes of defense signaling used to confer the resistance; genotype specific resistance in $B$. juncea to $H$. parasitica (Brassica downy mildew; isolates derived from $B$. juncea); species level (nonhost) resistance in both crucifers to Bremia lactucae (lettuce downy mildew) and an isolate of the $H$. parasitica race derived from Brassica oleracea; and nonhost resistance in $B$. juncea to $H$. arabidopsis. Broadspectrum powdery mildew resistance conferred by $R P W 8$ also was suppressed in Arabidopsis thaliana to two morphotypes of Erysiphe spp. following pre-infection with $A$. candida subsp. arabidopsis.
\end{abstract}

Additional keywords: oilseed mustard

Basic compatibility (Ellingboe 1976; Holub 2006) has been a term used to describe the intimate coevolved association that can exist between taxa (species or subspecies) of a plant and its adapted pathogens. To be adapted, the pathogen must intrinsically be able to evade or render ineffective the constitutive barriers and the inducible defenses of its compatible host. This pathogen also must possess the particular developmental and

Corresponding author: E. B. Holub; E-mail: eric.holub@warwick.ac.uk metabolic characteristics that are necessary for it to be able to harness the host's metabolism. Basic compatibility, however, can be observed only in the absence of natural intraspecific variation in disease resistance of the host, commonly mediated by pathogen receptor-like proteins, encoded by so-called resistance $(R)$ genes, that are capable of detecting elicitor molecules produced by an otherwise virulent pathogen (deWit 2007; Holub 2001, 2007; Staskawicz et al. 1995).

Some plant pathogens have evolved the ability to enhance the susceptibility of their host toward normally avirulent variants of the same or different pathogen species. In some cases, suppression of "nonhost" resistance to biotrophic pathogens from other host species has been demonstrated. Yarwood (1951) first described this phenomenon more than 50 years ago and, along with subsequent reports, it appears to be a common attribute of true fungi such as basidiomycete rust and ascomycete powdery mildew pathogens (Gill 1965; Heath, 1980; Lyngkjaer and Carver 2000; Moseman and Greeley 1964; Moseman et al. 1965; Ouchi and Oku 1981; Yarwood 1977). Interestingly, these potent defense-suppressive fungi have contrasting life cycles: growth and reproduction of powdery mildews is confined primarily to epidermal cells, whereas rust fungi colonize the mesophyll, often following penetration via stomata, and later reemerge by rupturing the epidermis with the formation of spore-bearing pustules.

The filamentous oomycete Albugo candida is descended from an aquatic nonfungal ancestor and belongs to the kingdom Stramenopiles (along with brown algae and diatoms) (Sogin and Silberman 1998). Despite the separate phylogeny of oomycetes and true fungi (kingdom Eumycota), A. candida causes disease in a manner similar to rust fungi, including penetration by asexual inoculum via stomata, mesophyll colonization of a compatible host tissue, and reproduction via spore-bearing pustules. Hence, the disease caused by A. candida has been referred to as white blister rust (Holub et al. 1995). As with basidiomycete rusts, compatible host tissue colonized by $A$. candida often is associated with chlorophyll retention (green islands) and growth malformation that is indicative of hormonal disturbance (Crute et al. 1994).

In our study, we were interested in determining whether basic compatibility of $A$. candida with its natural hosts can, as a consequence, suppress defense against secondary infection by other pathogens, similar to the previous reports for basidiomycete rusts. A. candida has the capacity under field conditions to elevate the incidence and severity of infection by Hyaloperonospora parasitica (Brassica downy mildew; formerly Peronospora parasitica) (Constantinescu and Fatehi 2002) in cru- 
cifer hosts. Both organisms frequently grow intimately together in leaf or stem tissue of the same crucifer host (Bains and Jhooty 1985; Chaurasia et al. 1982; Sansome and Sansome 1974), and dual infections by both pathogens cause significant yield losses in oilseed mustard crops of Brassica juncea (Bains and Jhooty 1979). Sequential inoculations in laboratory experiments have suggested that preinfection with virulent $A$. candida can suppress downy mildew resistance in brassicas to avirulent isolates of either $H$. parasitica or A. candida (Rimmer et al. 2000; Singh et al. 2002). A similar observation was reported for suppression of resistance to H. arabidopsis (Arabidopsis thaliana downy mildew; renamed as a distinct species by Goker and associates [2004]; supported by Rehmany and associates [2000]) in A. thaliana following preinfection with Albugo candida (Holub et al. 1993) (Fig. 1A).

White rust in natural populations of Arabidopsis thaliana is caused by a distinct subspecies of Albugo candida subsp. arabidopsis (Borhan et al. 2008) and offers an attractive model for investigating the molecular basis of broad-spectrum defense suppression by a biotrophic oomycete. From previous molecular genetic analyses of downy mildew resistance, there are numerous examples of receptor-like genes in Arabidopsis thaliana that vary in different modes of defense regulation (Eulgem et al. 2004; Holub 2001; McDowell et al. 2000; Tör et al. 2002) and, thus, provide contrasting examples for our sequential inoculation experiments involving the same preinfection treatment with Albugo candida subsp. arabidopsis. In addition, mutation of a zinc-finger protein called lesion-simulating disease (LSD)1 provides a useful tool for determining the potency of cell death suppression by A. candida subsp. arabidopsis. This mutant exhibits a highly sensitive "runaway cell death phenotype" when stimulated by conditions such as shifting mutant plants from a short- to long-day environment, or inoculating leaves with virulent or avirulent pathogens (Dietrich et al. 1997). Once initiated, the cell death spreads rapidly and usually results in premature death of the plant. However, virulent $A$. candida can colonize and complete its life cycle unrestricted, without inducing cell death in cotyledons or leaves of Arabidopsis thaliana lsdl (Holub and Beynon 1997).

In this study, we used $l s d l$ to determine how this mutant responds to secondary infection by an avirulent $H$. arabidopsis isolate following cell death suppression by Albugo candida subsp. arabidopsis. We quantified defense suppression by $A$. candida in sequential inoculation experiments using contrasting examples of both race and nonhost (species-level) resistance to downy mildew pathogens in Arabidopsis thaliana, and conducted similar experiments in a domestic relative, $B$. juncea, using a virulent isolate of Albugo candida race 2. In addition, we examined the impact of $A$. candida subsp. arabidopsis pre- infection in Arabidopsis thaliana on broad-spectrum powdery mildew resistance (conferred by $R P W 8$ ) (Xiao et al. 2001) and on temperature-sensitive resistance (accession Wassilewskija [Ws-3]) to the hemibiotrophic fungus Colletotrichum higginsianum (O'Connell et al. 2004).

\section{RESULTS}

\section{Albugo candida subsp. arabidopsis suppresses cell death in lsd1 mutant Arabidopsis thaliana but not when elicited by a hemibiotroph.}

Three avirulent isolates of $H$. arabidopsis (Cala2, Cand5, and Hiks1; all derived from U.K. Arabidopsis thaliana) and one $H$. parasitica isolate ( $\mathrm{P} 005$; representing a race derived from $B$. oleracea) all induced rapid cell death following inoculation in cotyledons of Arabidopsis thaliana Ws-lsdl. Infected seedlings shriveled and collapsed within $48 \mathrm{~h}$ after inoculation (Fig. 2A, left cotyledon). In wild-type Arabidopsis thaliana Ws-3, RPPl confers resistance to all three of the H. arabidopsis isolates, whereas resistance to $H$. parasitica $\mathrm{P}-005$ has not been genetically characterized. Similarly, Arabidopsis thaliana Col-lsdl seedlings shriveled and collapsed within $48 \mathrm{~h}$ of inoculation with avirulent $H$. arabidopsis isolates, including Cala2 (recognized in the Col-0 background by RPP2), Emwa1 (recognized by RPP4), Hiks1 (recognized by RPP7), and Cand5 (an example of polygenic resistance). An avirulent isolate of Albugo candida (A001; representing a race derived from B. oleracea) also elicited cell death in Arabidopsis thaliana Ws-lsdl that rapidly killed seedlings within $48 \mathrm{~h}$ of inoculation.

In contrast, the virulent isolate of Albugo candida subsp. arabidopsis (Acem1) colonized Ws-lsdl and Col-lsdl seedlings without eliciting cell death and, subsequently, sporulated in both genetic backgrounds (Fig. 2A, right cotyledon). Mutant $l s d l$ plants in both genetic backgrounds readily became systemically infected with Acem1; examples were observed that survived several months without the initiation of cell death or flowering and eventually died after gradual senescence at the 8- to 10-leaf stage with rust pustules erupting on most tissues (Fig. 2B, red-bordered inset). A sequential inoculation experiment was performed in which Col-lsdl was inoculated with $A$. candida subsp. arabidopsis Acem1 and, $24 \mathrm{~h}$ later, with $H$. arabidopsis Hiks1. Low levels of Hiks1 sporulation were observed on cotyledons that also supported Acem1 blisters, without the induction of cell death (Fig. 2C). Interestingly, the Ws3 virulent isolate of $H$. arabidopsis Emwa1 was effective in eliciting cell death in cotyledons of Ws- $l s d l$, but only 5 days after inoculation (dai), following extensive colonization and initiation of asexual sporulation (Fig. 2A, middle cotyledon).

Fig. 1. Preinfection (48 h) of wild-type Arabidopsis thaliana or Brassica juncea with a virulent isolate of Albugo candida (white blister rust) suppresses host defenses and, following secondary inoculation, enables avirulent mildew pathogens to colonize and reproduce. A, Sexual reproduction of avirulent Hyaloperonospora arabidopsis (Arabidopsis downy mildew; isolate Cala1) was observed in a juvenile leaf of Arabidopsis thaliana Columbia (Col-0), visible as hyaline, smooth, thick-walled oospores (left photograph, labeled Ho; revised from figure published in Holub et al. 1993) compared with the naturally golden-pigmented, rough-walled oospores of Albugo candida subsp. arabidopsis (labeled Ao). White rust pustules (labeled Ap) are also visible. Red dots indicate the relative location of $H$. arabidopsis oospores (leaf map on right). B, Cotyledons of Arabidopsis thaliana Col-5 inoculated solely with avirulent $H$. arabidopsis Cand5 and showing no symptoms (left) or sequentially inoculated with Albugo candida subsp. arabidopsis isolate Acem1 and Cand5 showing downy mildew sporangiophores (center, upper surface) and white blisters (right, lower surface). C, Cotyledons of Arabidopsis thaliana Ms-0 inoculated with a powdery mildew fungus (morphotype similar to Erysiphe cruciferarum) showing no fungal sporulation (left) or sequentially inoculated with Albugo candida subsp. arabidopsis Acem1 and the same fungal isolate showing growth of powdery mildew (center, upper surface) white rust blisters (right, lower surface). D, Pitting and necrotic flecks on cotyledons of Brassica juncea line 560-1 inoculated with an avirulent isolate of $H$. parasitica (IP10, race derived from Eruca sativa) (left) and sporulation of IP10 on the upper surface (center) of a cotyledon that was pre-infected with a virulent $A$. candida race 2 isolate (blisters visible on lower surface, right). E, Juxtaposition of hyphae of $A$. candida $(A c)$ and $H$. parasitica ( $H p$ ) in the mesophyll of a sequentially inoculated cotyledon of $B$. juncea (line 560). Arrowheads indicate a characteristic large, lobed haustorium of $H p$ compared with the much smaller, stalked haustorium of A. candida. F, Scanning electron photomicrograph of an Arabidopsis thaliana Ws-eds1 true leaf preinfected with Albugo candida subsp. arabidopsis Acem1 and, 48 h later, with Bremia lactucae B1096, showing a trichome characteristic of Arabidopsis thaliana and a single B. lactucae sporangiophore with characteristic sterigmata (inset diagram, far right, from Webster 1980). 
The fungus $C$. higginsianum IMI349061 was used to determine whether virulent $A$. candida Acem1 also could suppress cell death conferred by a hemibiotroph. We used Ws-3, which reportedly exhibits resistance to $C$. higginsianum at cool tem- peratures (O'Connell et al. 2004). At $20^{\circ} \mathrm{C}$, symptoms were clearly evident in Ws-3 cotyledons within 5 dai and moderate disease severity was observed 7 to 11 dai, indicating that the resistance was only partially effective under our experimental
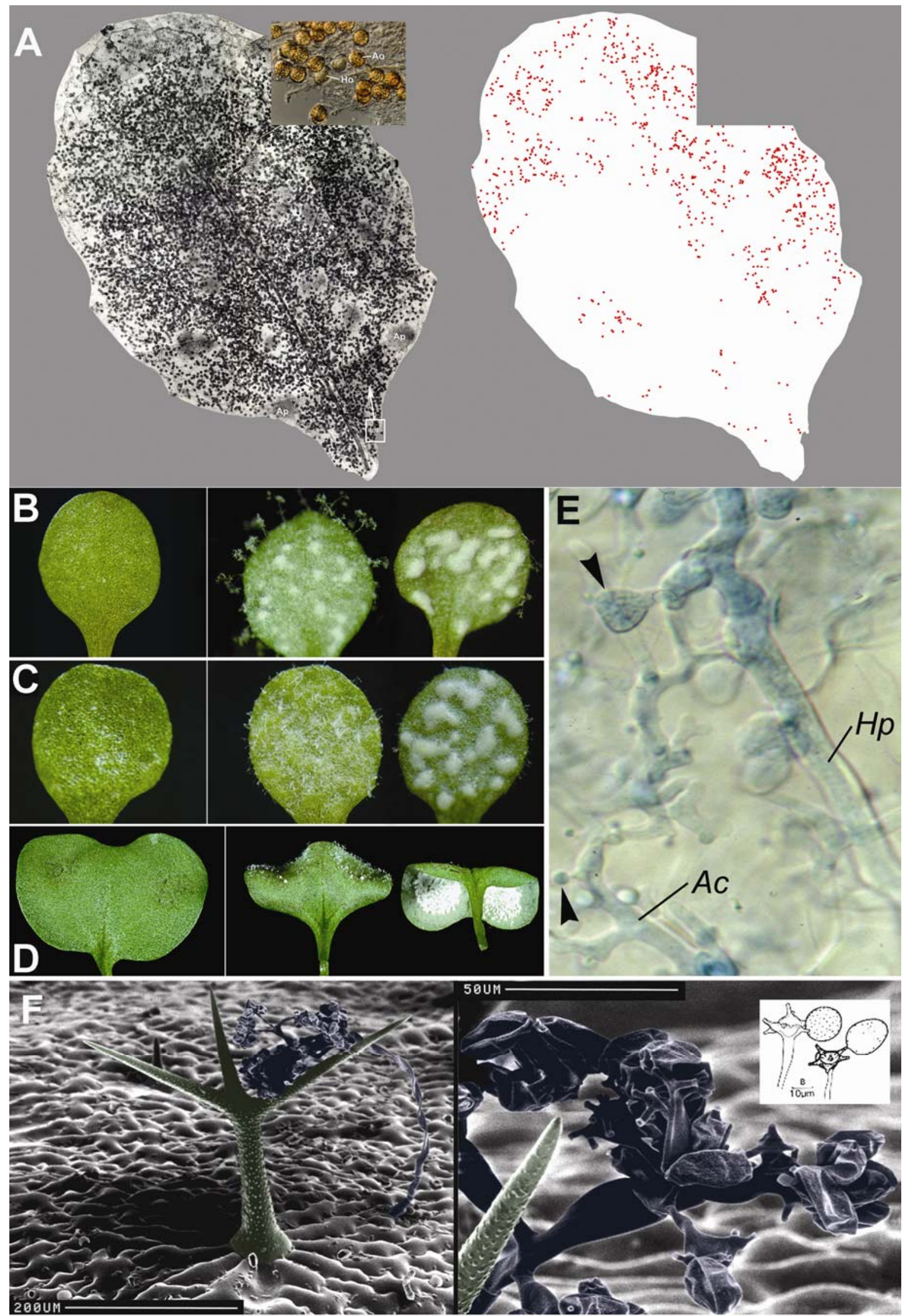
conditions (Fig. 2D, upper right; Table 1). Preinfection (48 h) with Acem1 had no significant effect on disease severity, neither enhancing nor reducing the partial resistance. A similar comparison was observed between both pathogen treatments in the Ws-eds1; however, this mutant appeared to be significantly more susceptible than Ws-3 $(P<0.001)$ to the necrotrophic stage of $C$. higginsianum (Fig. 2D, lower photos; Table 1). Interestingly, this indicated that the temperature-sensitive resistance to $C$. higginsianum in Ws-3 requires functional expression of the lipase-like protein $E D S 1$.

\section{Suppression of race-specific resistance in wild-type Arabidopsis thaliana.}

Sequential inoculation experiments were undertaken to determine the capacity of Albugo candida subsp. arabidopsis isolate Acem 1 to suppress downy mildew resistance in Arabidopsis thaliana to different avirulent isolates of $H$. arabidopsis. Arabidopsis thaliana seedlings were preinoculated with Acem $148 \mathrm{~h}$ before secondary inoculation with an avirulent $H$. arabidopsis isolate. In Col-0 seedlings, Acem1 significantly suppressed resistance to $H$. arabidopsis Hiks1, with an observed mean of 6.7 sporangiophores per cotyledon (Table 2). Acem1 also significantly enhanced sporulation in Col-0 by Cand5 and Cala2, with each of these $H$. arabidopsis isolates producing more than eight sporangiophores per cotyledon (Table 2; Fig. 1B). In other genetic backgrounds, preinfection with Acem1 enhanced sporulation to Hiks1 in Ler-0 and to Cala2 in Ws-3 (Table 2).

\section{Suppression of nonhost (species-level) resistance in Arabidopsis thaliana.}

Isolates of $H$. parasitica derived from brassica hosts are broadly avirulent (species level) in wild-type Arabidopsis thaliana. An isolate of $H$. parasitica (P005, representing a race derived from $B$. oleracea) was used in a sequential inoculation experiment following inoculation with Albugo candida subsp. arabidopsis Acem1 in both wild-type and mutant Arabidopsis thaliana. The highest level of sporulation was observed on sequential inoculated cotyledons of the mutant Ws-eds 1 (Table 2 ). As expected from the previous report by Parker and associates (1996), this Arabidopsis thaliana mutant exhibited partial susceptibility to P005 in the absence of Acem1, producing a mean of 1.2 sporangiophores per cotyledon. However, preinfection $(48 \mathrm{~h})$ with Acem 1 enhanced sporulation by P005 in Ws-eds 1 approximately sevenfold. In wild-type Arabidopsis thaliana, Acem 1 also significantly $(P<0.01)$ suppressed resistance to $H$. parasitica $\mathrm{P} 005$. No sporulation of downy mildew was observed in the absence of Acem1, but a mean of 1.5 sporangiophores per cotyledon was observed in sequentially inoculated seedlings.

Albugo candida subsp. arabidopsis Acem1 also suppressed resistance of Arabidopsis thaliana to the lettuce downy mildew pathogen Bremia lactucae (Table 2; Fig. 1F). In the absence of Acem1, Bremia lactucae did not sporulate in either wild-type Arabidopsis thaliana or mutant Ws-eds1 seedlings, whereas Acem1 enabled the sporulation of Bremia lactucae in wildtype (significant at $P<1 \%$ ) Arabidopsis thaliana and mutant Ws-edsl (significant at $P<0.05 \%$ ).

\section{Suppression of downy mildew resistance in wild-type Brassica juncea.}

Sequential inoculation experiments were performed on Brassica juncea line 560-1, using a virulent Albugo candida race 2 isolate (Bihar-SP, derived from $B$. juncea) for preinfection of cotyledons. Interestingly, sequential inoculations on $B$. juncea with virulent $H$. parasitica isolate IP05 revealed that the presence of $A$. candida Bihar-SP significantly $(P<0.001)$ increased the level of downy mildew sporulation in this com- patible host-isolate interaction. Similarly, A. candida Bihar-SP suppressed genotype-specific resistance to an avirulent isolate of $H$. parasitica (IP00A, derived from B. juncea), enabling it to sporulate heavily on cotyledons (Table 3 ). In the absence of A. candida Bihar-SP, H. parasitica isolate IP00A produced extensive necrotic flecks and did not sporulate. A single dominant gene confers resistance to this downy mildew isolate in $B$. juncea line 560-1 (Nashaat et al. 1998)

In addition, experiments on B. juncea line 560-1 revealed that preinfection with $A$. candida isolate Bihar-SP suppressed resistance toward downy mildew pathogens collected from lettuce (Lactuca sativa) and other crucifer species (Table 3): $B$. rapa, B. napus, B. oleracea, Eruca sativa, Arabidopsis thaliana, and Cherianthus cherii, as well as from lettuce ( $L$. sativa). Bihar-SP significantly enhanced $(P<0.01)$ the number of sporangiophores of $H$. parasitica IP00A (origin B. juncea), PP6 (origin B. oleracea), P003 (origin B. napus), IP09 (origin $B$. rapa), and IP10 (origin E. sativa) on sequentially inoculated $B$. juncea; heavy sporulation of the downy mildew pathogen was seen in each interaction. The effect of Bihar-SP on the number of sporangiophores produced by $H$. parasitica isolate WF1 (from $C$. cherii), was highly significant $(P<0.004)$. Again, heavy sporulation was seen on the upper surface of sequentially inoculated cotyledons. Examples of interaction phenotypes observed on seedlings of $B$. juncea are shown in Figure 1D. The H. arabidopsis isolate Cala2 and the Bremia lactucae isolate BL/96 from lettuce were able to sporulate on preinfected Brassica juncea line 560-1 at very low frequency (Table 2). In the absence of Albugo candida Bihar-SP, all of the avirulent downy mildews tested produced necrotic "pitting" lesions on B. juncea line 560-1.

A. candida (including both Acem1 and Bihar-SP) is distinguishable microscopically from $H$. arabidopsis and $H$. parasitica in cleared host tissue: $A$. candida produces minute, spherical haustoria which are attached to hyphae by thin necks, whereas the downy mildew parasites produce much thicker hyphae and club-shaped haustoria (Fig. 1E). In sequentially inoculated tissue of either Arabidopsis thaliana or $B$. juncea, the haustoria of downy mildew parasites typically were formed in host cells adjacent to ones that contained haustoria of either Acem1 or Bihar-SP in their respective compatible host tissue (data not shown).

\section{Suppression of powdery mildew resistance in Arabidopsis thaliana.}

Albugo candida subsp. arabidopsis Acem1 also suppressed resistance of Arabidopsis thaliana to powdery mildew, an ascomycete fungus. Resistant Arabidopsis thaliana Moscow (Ms-0) contains RPW8, which naturally confers broad-spectrum resistance to several powdery mildew species (Xiao et al. 2001). When this accession was inoculated solely with a powdery mildew isolate (morphotype similar to Erysiphe cruciferarum), no measurable fungal growth or sporulation was observed 7 dai; whereas $48 \mathrm{~h}$ of preinfection with Acem 1 resulted in $18 \%$ coverage of cotyledons with powdery mildew mycelium (Table 2; Fig. 1C). Similarly, transgenic Arabidopsis thaliana Col-0:: RPW8 inoculated solely with the same powdery mildew isolate showed $11 \%$ cotyledon coverage, compared with up to $38 \%$ coverage in cotyledons that were preinfected for $48 \mathrm{~h}$ with $\mathrm{Al}$ bugo candida subsp. arabidopsis Acem1 (Table 2). The differences in powdery mildew between presence and absence of Acem1 were statistically significant $(P<0.01)$ in both genetic backgrounds of Arabidopsis thaliana. With a second, highly virulent powdery mildew isolate (morphotype similar to Erysiphe orontii), RPW8 resistance appeared to be fully suppressed in transgenic Col-0::RPW8 (Fig. 3) following $48 \mathrm{~h}$ of preinfection by Acem1. 


\section{DISCUSSION}

We have described examples demonstrating that basic compatibility of Albugo candida in two crucifer hosts involves broad-spectrum suppression of cell death and innate immunity, including the runaway cell death phenotype of the Arabidopsis thaliana lsdl mutant in a manner that is sustained even after secondary infection with an avirulent pathogen; several examples of genotype-specific resistance to downy mildew in Arabidopsis thaliana and B. juncea that, in the case of Arabidopsis thaliana, differ in the type of resistance $(\mathrm{R})$ protein involved and the phenotypic manifestation of defense that is conferred; species-level (nonhost) resistance in Arabidopsis thaliana and $B$. juncea to an isolate of the $H$. parasitica race derived from B. oleracea and to Bremia lactucae (lettuce downy mildew);

Table 1. Mean disease severity caused by infection of Arabidopsis thaliana with the hemibiotroph fungus Colletotrichum higginsianum (IMI349061) in seedlings that were noninoculated or preinfected (48 h) with Albugo candida subsp. arabidopsis $(\text { Acem } 1)^{\mathrm{a}}$

\begin{tabular}{|c|c|c|c|c|c|c|}
\hline \multirow[b]{2}{*}{ Accession $^{b}$} & \multirow[b]{2}{*}{ Dai } & \multirow[b]{2}{*}{$\operatorname{Age}^{c}$} & \multicolumn{2}{|c|}{$\begin{array}{c}\text { No } \\
\text { Acem1 }\end{array}$} & \multicolumn{2}{|c|}{$\begin{array}{c}\text { Acem1 } \\
\text { preinfection }\end{array}$} \\
\hline & & & Mean & SE & Mean & SE \\
\hline \multirow[t]{4}{*}{ Ws-3 } & 7 & 7 & 4.0 & \pm 0.68 & 2.6 & \pm 0.50 \\
\hline & $\ldots$ & 10 & 3.7 & \pm 0.69 & 4.0 & \pm 0.48 \\
\hline & 11 & 7 & 4.0 & \pm 0.62 & 4.9 & \pm 0.49 \\
\hline & $\ldots$ & 10 & 4.4 & \pm 0.43 & 4.3 & \pm 0.34 \\
\hline \multirow[t]{4}{*}{ Ws-eds 1} & 7 & 7 & 4.6 & \pm 0.53 & 4.0 & \pm 0.48 \\
\hline & $\ldots$ & 10 & 4.1 & \pm 0.36 & 4.6 & \pm 0.34 \\
\hline & 11 & 7 & 4.7 & \pm 0.56 & 4.6 & \pm 0.47 \\
\hline & $\ldots$ & 10 & 4.7 & \pm 0.40 & 5.4 & \pm 0.35 \\
\hline
\end{tabular}

${ }^{a}$ Dai $=$ days after inoculation when the disease severity was assessed using a six-class scale (where class $1=$ no symptoms observed and class $6=$ dead seedling) and $\mathrm{SE}=$ standard error. Summary of statistical analysis: Acem $1=$ not significant, accession and dai significant at $P<0.001$.

${ }^{\mathrm{b}}$ Arabidopsis thaliana accession.

${ }^{c}$ Seedling age in days when the seedlings were inoculated with $C$. higginsianum. and broad-spectrum $R P W 8$-mediated resistance (Xiao et al. 2001) to powdery mildew in Arabidopsis thaliana. The two Albugo candida isolates used in this study represent divergent groups within the species (Borhan et al. 2008) and, thus, demonstrate that suppression of downy mildew resistance is a species-level characteristic of $A$. candida. Interestingly, A. candida significantly enhanced sporulation of a virulent isolate of $H$. arabidopsis in Brassica juncea. However, preinfection with A. candida does not appear to protect a compatible host from fungal-mediated cell death, because this treatment had no measurable effect on the severity of disease caused by the hemibiotrophic fungus $C$. higginsianum in Arabidopsis thaliana Ws-3 (O'Connell et al. 2004).

We specifically chose isolates of $H$. arabidopsis for this study that are recognized by different RPP (resistance to Hyaloperonospora parasitica) proteins and are known to confer resistance through various defense pathways, as defined by molecular analyses of enhanced susceptibility mutants. For example, $R$ genes in Arabidopsis thaliana Col-0 represent several interesting examples, including digenic $R P P 2$ (that recognizes isolate Cala2), which confers resistance that is fully dependent on the expression of a lipase-like protein called EDS1 (Aarts et al. 1998); polygenic resistance (recognizing Cand5), involving at least three complementary $R$ genes, which is fully dependent on a membrane-associated protein called NDR1 (Century et al. 1997; E. B. Holub, unpublished); and monogenic RPP7 (recognizing Hiks1), which confers cumulative resistance by altering regulation of EDS1, NDR1, and a further unknown defense component (McDowell et al. 2000). Defense signaling in each of these examples requires the expression of AtSGT1b, a protein that is conserved across kingdoms as a key component in ubiquitin-mediated proteolysis (Austin et al. 2002; Tör et al. 2002, 2003). For contrasting examples, resistance is conferred via an AtSGT1b-independent defense signaling pathway in the cases of Cala2, which is recognized by RPP1 in Arabidopsis thaliana Ws-3, and Hiks1, which is recognized by RPP27 in Ler-0 (Austin et al. 2002; Tör et al. 2002). Albugo candida

Table 2. Mean sporulation of avirulent downy mildew isolates (measured as the mean number of sporangiophores per cotyledons) and an avirulent powdery mildew isolate (percent leaf area covered with fungal hyphae and sporulation) in different Arabidopsis thaliana accessions that were either preinfected (48 $\mathrm{h}$ ) or noninfected (control) by a virulent isolate of Albugo candida subsp. arabidopsis (Acem1)

\begin{tabular}{|c|c|c|c|c|c|c|c|}
\hline Pathogen species & Isolate (original host) & Accession $^{a}$ & $\begin{array}{c}R \text { gene } \\
{\text { (and defense regulation })^{b}}^{b}\end{array}$ & $\begin{array}{l}\text { No. of } \\
\text { cotyledons }\end{array}$ & $\begin{array}{c}\text { No } \\
\text { Acem1 }\end{array}$ & $\begin{array}{c}\text { Acem1 } \\
\text { preinfected }\end{array}$ & Significance \\
\hline \multirow[t]{5}{*}{$\begin{array}{l}\text { Hyaloperonospora } \\
\text { arabidopsis }\end{array}$} & $\begin{array}{l}\text { Cala2 } \\
\text { (Arabidopsis thaliana) }\end{array}$ & Col-0 & RPP2 (AtSGT1b, EDS1) & 240 & $<0.1( \pm 0.00)$ & $8.4( \pm 0.80)$ & $<0.01$ \\
\hline & & Ws -3 & $R P P 1-W s A(E D S 1)$ & 160 & $0.0( \pm 0.00)$ & $6.0( \pm 0.60)$ & $<0.01$ \\
\hline & $\begin{array}{l}\text { Hiks } 1 \\
\text { (Arabidopsis thaliana) }\end{array}$ & Col-0 & $\begin{array}{l}\text { RPP7 (AtSGT1b, EDS1, } \\
\text { NDR1 + other })\end{array}$ & 160 & $0.0( \pm 0.00)$ & $6.7( \pm 0.60)$ & $<0.01$ \\
\hline & & Ler-0 & $\begin{array}{l}R P P 7, R P P 27(A t S G T 1 b, E D S 1, \\
N D R 1+\text { other })\end{array}$ & 120 & $0.0( \pm 0.00)$ & $2.4( \pm 0.60)$ & $<0.01$ \\
\hline & $\begin{array}{l}\text { Cand5 } \\
\text { (Arabidopsis thaliana) }\end{array}$ & Col-0 & polygenic $(A t S G T 1 b, N D R 1)$ & 260 & $0.1( \pm 0.08)$ & $8.7( \pm 1.60)$ & $<0.01$ \\
\hline \multirow[t]{3}{*}{ H. parasitica } & $\begin{array}{l}\mathrm{P}-005 \\
\quad(\text { Brassica oleracea })\end{array}$ & Col-0 & nd & 120 & $0.0( \pm 0.00)$ & $1.5( \pm 0.30)$ & $<0.01$ \\
\hline & & Ws-3 & nd (EDS1 + other) & 40 & $0.0( \pm 0.00)$ & $0.9( \pm 0.00)$ & $<0.01$ \\
\hline & & Ws-eds 1 & $\ldots$ & 80 & $1.2( \pm 0.30)$ & $7.3( \pm 1.40)$ & $<0.05$ \\
\hline \multirow[t]{3}{*}{ Bremia lactucae } & BL/96 (Lactuca sativa) & Col-0 & nd & 40 & $0.0( \pm 0.00)$ & $0.8( \pm 0.000)$ & $<0.05$ \\
\hline & & Ws-3 & nd & 40 & $0.0( \pm 0.00)$ & $0.8( \pm 0.00)$ & $<0.01$ \\
\hline & & Ws-eds 1 & $\ldots$ & 160 & $0.0( \pm 0.00)$ & $1.8( \pm 0.60)$ & $<0.01$ \\
\hline \multirow[t]{2}{*}{ Erysiphe sp. ${ }^{\mathrm{c}}$} & $\begin{array}{l}\text { Unnamed } \\
\text { (Arabidopsis thaliana) }\end{array}$ & $\mathrm{Col}+R P W 8$ & $R P W 8(E D S 1)$ & $\ldots$ & $11 \%$ & $38 \%$ & $<0.01$ \\
\hline & & Ms-0 & $R P W 8(E D S 1)$ & $\ldots$ & $0 \%$ & $18 \%$ & $<0.01$ \\
\hline
\end{tabular}

a Arabidopsis thaliana accession. Col $+R P W 8=$ Columbia transgenic line T-B6 (containing cosmid B6 and both functional copies of $R P W 8$ ) described by Xiao and associates (2001).

${ }^{\mathrm{b}} R=$ resistance gene. $R P P$ genes reviewed in Holub 2001, 2007; AtSGT1b = homologue of SGT1 in yeast (Tör et al. 2002); EDS1 = enhanced disease susceptibility (Aarts et al. 1998); NDRl = non-race-specific disease resistance (Century et al. 1997). Description of the resistance ( $R$ ) genes is provided in the following references: Botella et al. 1998; Holub 2007; McDowell et al. 2000; Sinapidou et al. 2002; Tör et al. 2002; Xiao et al. 2001; nd = not determined.

${ }^{\mathrm{c}}$ Morphologically similar to Erysiphe cruciferarum; inoculum collected from resident population on Brassica oleracea and Arabidopsis thaliana plants in Warwick-HRI glasshouses. 

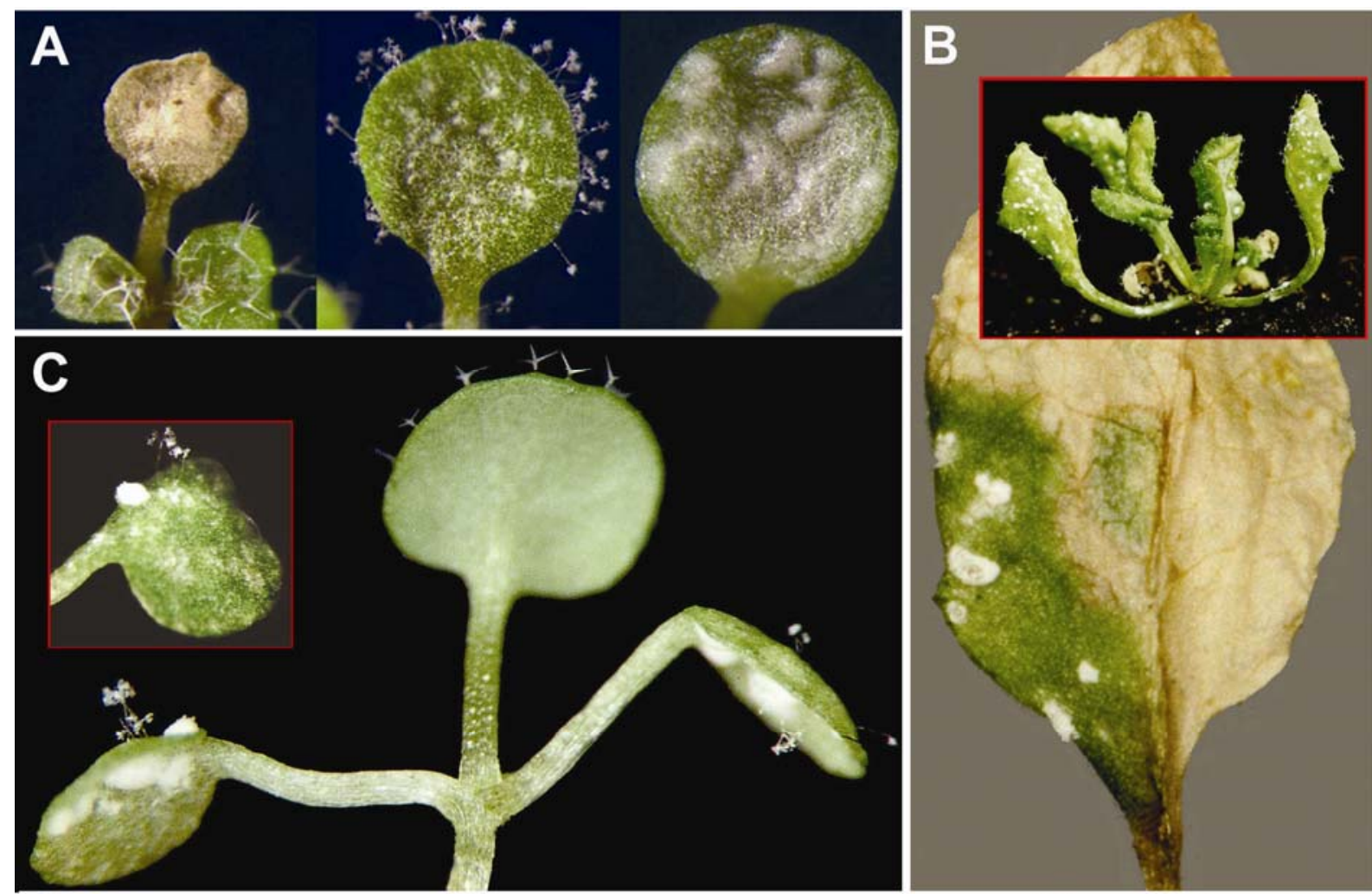

D

A. candida pre-infected

\section{C. higginsianum}

+ C. higginsianum

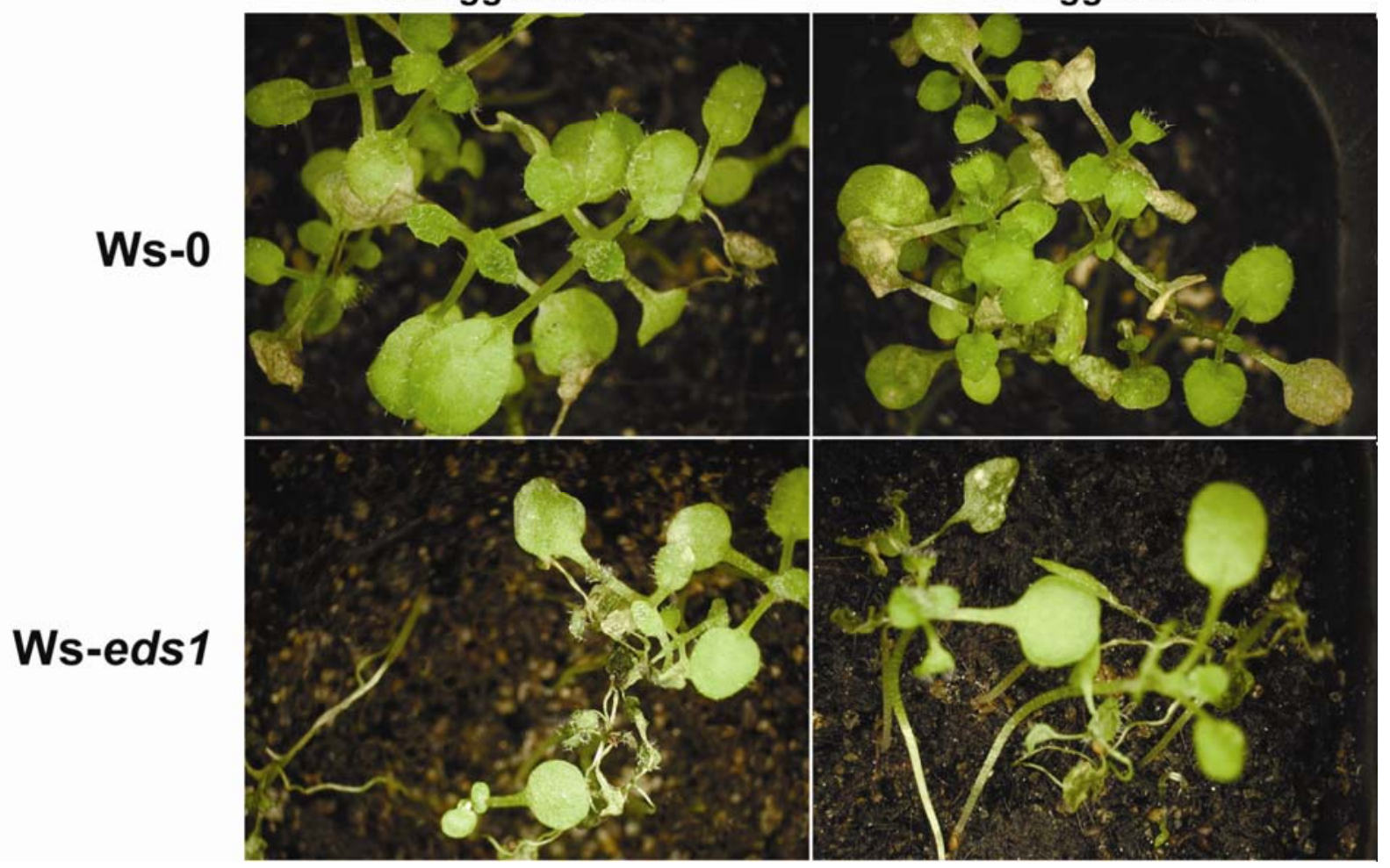

Fig. 2. Albugo candida subsp. arabidopsis (isolate Acem1) suppresses "runaway cell death" that is readily inducible in the Arabidopsis thaliana lsdl mutant but has no visible impact on seedling mortality caused by the necrotrophic stage of the hemibiotrophic fungus Colletotrichum higginsianum (IMI349061). A, Cotyledons of Ws-lsdl mutant seedlings exhibit rapid cell death following inoculation with avirulent isolates of Hyaloperonospora parasitica (left, photographed $24 \mathrm{~h}$ after inoculation with isolate P005; entire seedling was dead $24 \mathrm{~h}$ later) or delayed cell death following heavy downy mildew sporulation when inoculated with a virulent isolate of $\mathrm{H}$. parasitica (middle, 7 days after inoculation with isolate Emwa1; seedling was dead $48 \mathrm{~h}$ later); whereas no cell death or restriction of parasite reproduction occurs following inoculation with Albugo candida subsp. arabidopsis Acem1 (right, 7 days after inoculation). B, Systemic infection of Ws-lsdl by Acem 1 protected the entire plant from the cell death phenotype (red box inset, the plant ceased at nine-leaf stage and survived for 6 months, eventually senescing similar to a systemically infected wild-type plant). C, Cotyledons of Col-lsd 1 preinoculated with Acem 1 followed $24 \mathrm{~h}$ later by inoculation with Col-avirulent $H$. parasitica (isolate Hiks1) did not exhibit cell death. D, Preinfection with Acem1 (48 h) provided no visible protection from seedling mortality inflicted by secondary infection by $C$. higginsianum in either wild-type Ws- 3 or the Ws-eds 1 mutant. 
subsp. arabidopsis (Acem1) suppressed resistance to downy mildew in all of the above examples to varying degrees. Similarly, a virulent isolate of $A$. candida race 2 (Bihar-SP) suppressed genotype-specific resistance of $B$. juncea to $H$. parasitica IP00A, which is conferred by a single dominant gene (Nashaat et al. 1998); interestingly, it also significantly enhanced susceptibility to a virulent $H$. parasitica isolate (IP05).

Although the ability of $A$. candida to suppress $R$-gene-mediated resistance is broad spectrum, it does not appear to be universal. Most notable is the rare Arabidopsis thaliana gene RACl that confers white rust resistance to Albugo candida subsp. arabidopsis, including the Col-virulent isolate Acem1 used in our study. This gene encodes a Toll-interleukin receptor-like nucleotide-binding leucine-rich repeat (TIR-NB-LRR) receptor-like protein that is structurally similar to the molecularly characterized $R P P$ genes mentioned above and also confers resistance via EDS1-signaling (Borhan et al. 2004). White rust resistance is an uncommon trait in Arabidopsis thaliana, occurring in $<10 \%$ of Arabidopsis thaliana accessions across a worldwide collection, and this type of disease resistance is rarely conferred by RACl (Borhan et al. 2001; Holub in press; Holub et al. 1995). Major advances have been achieved recently in the molecular characterization of oomycete "effector" proteins from Phytophthora spp. and H. arabidopsis that are

Table 3. Mean sporulation of a virulent and several avirulent downy mildew isolates in Brassica juncea cotyledons (accession 560-1) that were either preinfected $(48 \mathrm{~h})$ or noninfected (control) with a virulent isolate of Albugo candida race 2 (Bihar-SP) ${ }^{\mathrm{a}}$

\begin{tabular}{|c|c|c|c|c|c|c|c|}
\hline \multirow[b]{2}{*}{ Species, isolate ${ }^{d}$} & \multirow[b]{2}{*}{ Maintenance host ${ }^{\mathrm{e}}$} & \multicolumn{3}{|c|}{ Experiment $1^{b}$} & \multicolumn{3}{|c|}{ Experiment $2^{c}$} \\
\hline & & None & Bihar-SP & Significance & None & Bihar-SP & Significance \\
\hline \multicolumn{8}{|l|}{ Hyaloperonospora parasitica } \\
\hline IP05 (B. juncea) & $4.8 \pm 0.7$ & $2.9 \pm 0.7$ & $3.4 \pm 0.4$ & ns & $0.9 \pm 0.1$ & $1.6 \pm 0.1$ & $<0.001$ \\
\hline IP00A (B. juncea $)$ & $3.4 \pm 0.4$ & 0 & $2.4 \pm 0.5$ & 0.03 & 0 & $1.3 \pm 0.1$ & $<0.001$ \\
\hline IP09 $($ B. rapa $)$ & $3.6 \pm 0.7$ & 0 & $2.2 \pm 0.3$ & 0.03 & 0 & $1.6 \pm 0.2$ & $<0.001$ \\
\hline PP6 (B. oleracea) & $6.5 \pm 0.5$ & 0 & $2.7 \pm 0.4$ & 0.03 & 0 & $0.9 \pm 0.1$ & $<0.001$ \\
\hline P003 (B. napus) & $5.4 \pm 0.6$ & 0 & $3.5 \pm 0.6$ & 0.03 & 0 & $0.8 \pm 0.1$ & $<0.001$ \\
\hline IP10 (Eruca sativa) & $3.5 \pm 0.5$ & 0 & $1.6 \pm 0.3$ & 0.03 & 0 & $2.1 \pm 0.2$ & $<0.001$ \\
\hline WF1 (Cherianthus cherii) & $4.3 \pm 0.8$ & 0 & $0.1 \pm 0.1$ & 0.03 & 0 & $0.01 \pm 0.003$ & $<0.004$ \\
\hline \multicolumn{8}{|l|}{ H. arabidopsis } \\
\hline Cala2 (Arabidopsis thaliana) & $4.3 \pm 0.5$ & 0 & $0.1 \pm 0.1$ & 0.03 & 0 & $0.01 \pm 0.01$ & ns \\
\hline \multicolumn{8}{|l|}{ Bremia lactucae } \\
\hline BL/96 (Lactuca sativa) & $21 \pm 1.0$ & 0 & $<0.01$ & ns & 0 & $<0.01$ & ns \\
\hline
\end{tabular}

${ }^{\mathrm{a}}$ None $=$ no Bihar-SP and Bihar-SP $=$ preinfected.

${ }^{\mathrm{b}}$ Spore production was measured directly as the number of condiosporangia per square centimeter $\left(\times 10^{4}\right)$ of cotyledon surface produced by the avirulent pathogen, 7 days after inoculation (dai); ns = not significant.

${ }^{\mathrm{c}}$ Sporulation was measured as the number of sporangiophores per square centimeter $\left(\times 10^{3}\right)$ of cotyledon surface produced by the avirulent pathogen 7 dai

${ }^{\mathrm{d}}$ Downy mildew species and isolate (original host). IP05 is virulent on accession line 560-1, and all other isolates are avirulent.

${ }^{\mathrm{e}}$ The respective susceptible host for each downy mildew isolates includes: B. juncea, PPBJ-1; B. rapa, RES-BR-263; B. oleracea, cv. Billabong; B. napus, cv. Capricorn; Eruca sativa, cv. Taramira; Cherianthus cherii, cv. Fairlady; Arabidopsis thaliana, Ws-eds1; and L. sativa, cv. Cobham Green.

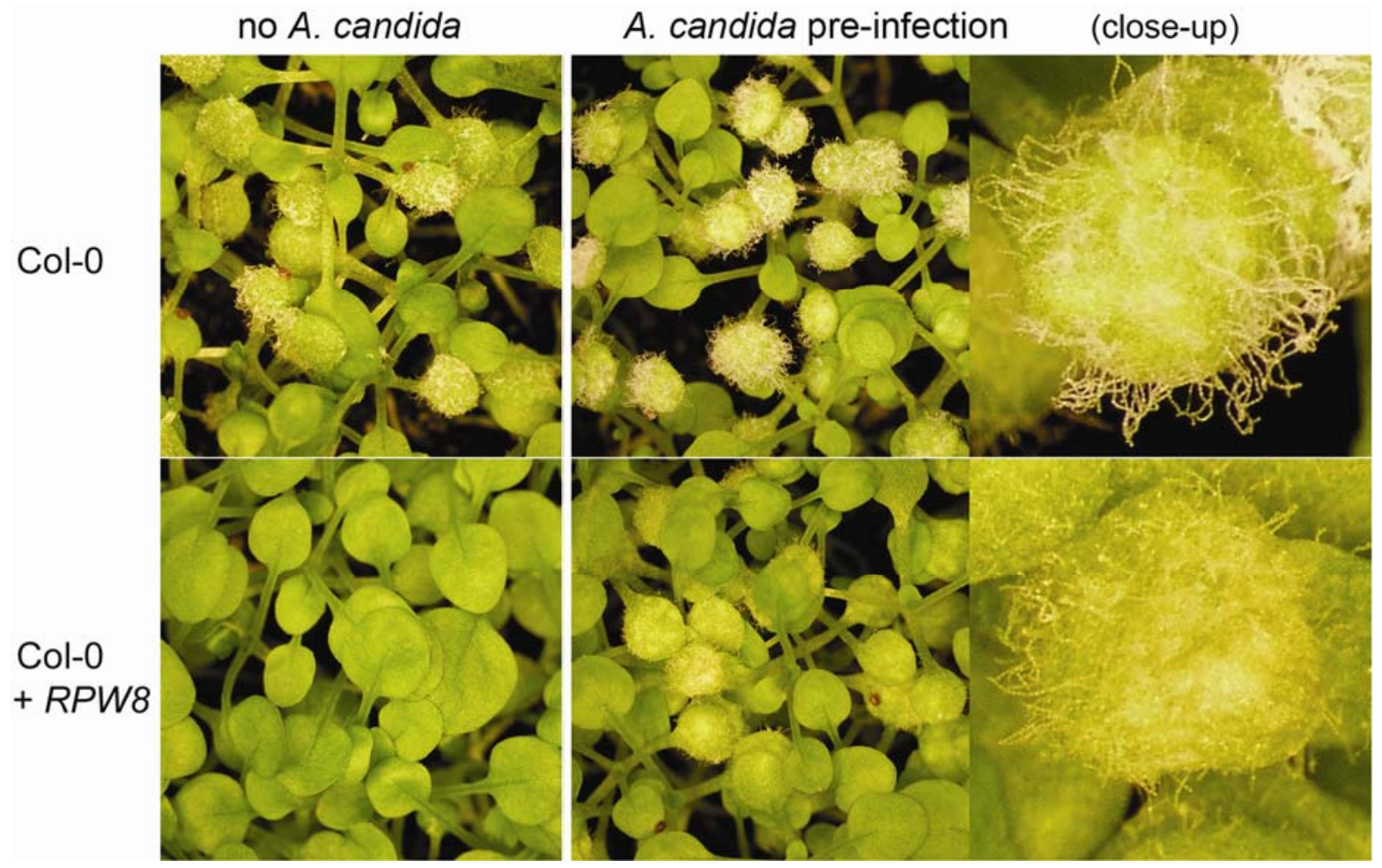

Fig. 3. Preinfection ( $48 \mathrm{~h}$ ) of cotyledons with Albugo candida subsp. arabidopsis (isolate Acem1) fully suppressed powdery mildew resistance conferred by $R P W 8$ in transgenic Arabidopsis thaliana Col-0. All seedlings shown in these photographs were inoculated with an isolate of powdery mildew fungus (a morphotype similar to Erysiphe orontii, producing long chains of conidia, top right; and highly virulent in Col-0, top left). A similar amount of hyphal growth and sporulation by the powdery mildew fungus was observed only in Col- $R P W 8$ that was preinfected with Acem 1 (bottom center and right). 
secreted from the parasite into the host and, if recognized by a matching $R$ gene, can elicit innate immunity (Kamoun 2006). The current emphasis is focused on a large family of proteins with a shared "RLR" domain that generally is thought to indicate targeting of the so-called "effector" proteins for activity within the host cytoplasm (Whisson et al. 2007; Win et al. 2007). Numerous apoplastic effectors also are anticipated in oomycetes (Kamoun 2006; Whisson et al. 2007). Similarly, molecular characterization of Albugo candida effector proteins will be necessary to resolve whether RAC1 enables Arabidopsis thaliana to recognize an Albugo candida subsp. arabidopsis effector that otherwise would suppress innate immunity in the absence of RAC1, or that defense suppression is an independent effector-mediated process which is preempted by RAC1mediated recognition of an alternative avirulence protein. Identification of RACl as a gene encoding a TIR-NB-LRR protein, which is predicted be to located in the cytoplasm, suggests that the defense suppression is initiated by an $A$. candida subsp. arabidopsis effector within the host cell. For instance, RAC1 may guard the host protein targeted by the parasite suppressor.

The molecular basis of species-level (nonhost) resistance in Arabidopsis thaliana and B. juncea to downy mildew parasites from other host species is currently unknown. However, it is evident from Arabidopsis thaliana mutants such as edsl that parasite recognition (mediated by $R$ genes and induced defense) most likely is involved. It also appears that oomycetes from brassicas and lettuce are at least partially pathogenically competent (i.e., equipped to complete their life cycle) in the "nonhost" Arabidopsis thaliana (Holub and Cooper 2004; Parker et al. 1996). In our current study, the eds1 mutation in the Arabidopsis thaliana Ws-3 genetic background partially diminished nonhost resistance to the $H$. parasitica isolate P005 collected from $B$. oleracea, as previously reported (Parker et al. 1996). Preinfection of wild-type Ws-3 with Albugo candida subsp. arabidopsis also enhanced P005 susceptibility to a degree similar to that observed with P005 on its own in Ws-eds1. The combined effect in cotyledons of the eds 1 mutant following A. candida subsp. arabidopsis preinfection was as high a level of sporulation by the $H$. parasitica isolate as was observed for any normally compatible $H$. arabidopsis isolate in Arabidopsis thaliana. This indicates that isolates specifically adapted to alternative hosts (such as B. oleracea) are still fully competent pathogens in Arabidopsis thaliana once the defense process has been negated. Similar results were observed in $B$. juncea with $H$. parasitica isolates that were collected from other Brassica spp., including $B$. oleracea, B. rapa, and $B$. napus. Each of these isolates represented subtaxa that exhibit a high degree of specialization to their host species of origin (Sherriff and Lucas 1990).

In the most extreme example, the lettuce downy mildew isolate of Bremia lactucae BL/96 was capable of sporulating only in cotyledons that were preinfected with Albugo candida, and this was further enhanced in an eds 1 background. The low levels of sporulation in these examples and also in Brassica juncea suggest that either Bremia lactucae is not fully adapted as a parasite in crucifer hosts or there is residual resistance or inaccessibility that still constrains development of Bremia lactucae. Similar parasite or host factors may explain the very low level of sporulation by $H$. arabidopsis isolate Cala2 in Brassica juncea cotyledons that were preinfected with $A$. candida race 2.

Recently, research on nonhost resistance has begun to elucidate the host genes that govern inaccessibility rather than induced defense (Holub and Cooper 2004). For example, Yun and associates (2003) demonstrated that two lipase-like genes, $P A D 4$ and EDS1, are involved in the defense of Arabidopsis thaliana against Blumeria graminis f. sp. tritici (barley powdery mildew). Lipka and associates (2005) subsequently demonstrated that PEN2 (a glycosyl hydrolase) is a protein that restricts the ingress of pea (E. pisi) and barley powdery mildews, thus conferring inaccessibility or "preinvasion" defense. The Arabidopsis thaliana eds1/pen 2 double mutant was even more susceptible to both parasites, and supported sporulation by $E$. pisi. The authors concluded that pre- and post-invasion defense mechanisms both are involved in nonhost resistance to powdery mildew in Arabidopsis thaliana. Therefore, it will be interesting to determine whether Albugo candida subsp. arabidopsis is capable of suppressing the preinvasion mechanisms that restrict growth of E. pisi in Arabidopsis thaliana, or whether it can further enhance susceptibility of the eds1 pen 2 double mutant to Blumeria graminis. Additional sequential inoculation experiments with other types of pathogens such as hemibiotrophs or necrotrophs also should be attempted. For example, results with the hemibiotrophic fungus $C$. higginsianum from our study indicated that preinfection of Arabidopsis thaliana Ws-3 or Ws-eds1 with Albugo candida subsp. arabidopsis Acem1 did not significantly affect the amount of seedling mortality caused by $C$. higginsianum isolate IMI 349061 at $20^{\circ} \mathrm{C}$ that was favorable for this hemibiotroph (O'Connell et al. 2004). This indicates that there are further limits (in addition to the $R A C l$ example described above) to the suppressive effects induced in Arabidopsis thaliana by preinfection with Albugo candida subsp. arabidopsis, which will relate directly to the developmental stage of the host and environmental conditions.

The suppressive effect of $A$. candida appeared to be nonsystemic and sustained by the parasite at least until the onset of host senescence. The sustained effect of defense suppression is clearly evident in the survival of Col-lsdl and Ws- $l s d l$ for several months following Acem1 infection, and despite secondary challenge with an avirulent downy mildew isolate. The effect was nonsystemic because enhanced downy mildew susceptibility was observed only when $A$. candida (readily visible by rust pustules) also was present in the same host tissue. Microscopic examination indicated that defense suppression may involve a local signal because haustoria produced by each of the oomycete parasites were never observed within the same host cell. Preliminary experiments with Brassica juncea (data not shown), in which one cotyledon was inoculated with $A$. candida race 2 and, $24 \mathrm{~h}$ later the opposite cotyledon was inoculated with an avirulent isolate of $H$. parasitica, showed no suppression of downy mildew resistance in the second cotyledon, suggesting that no long-distance signal for defense suppression is emitted by preinfection with $A$. candida infection.

The phenomenon of defense suppression is not limited to $A$. candida but extends into many other pathosystems. Over half a century ago, Yarwood (1951) found that bean rust (caused by a basidiomycete fungus) was able to suppress the resistance of bean toward viruses collected from other hosts. Similarly, Gill (1965) observed that sunflower plants preinfected with virulent rust, Puccinia helianthi, were more susceptible toward viruses, including Tobacco necrosis virus, Cucumber mosaic virus, Artichoke latent virus, and Cabbage mosaic virus. The breadth of this phenomenon also extends to monocotyledonous hosts in which powdery mildew acts as the suppressor; for example, wheat powdery mildew, Blumeria graminis f. sp. tritici (an ascomycete fungus), can suppress resistance in wheat to the barley powdery mildew pathogen Blumeria graminis f. sp. hordei (Moseman and Greeley 1964); and vice versa (Moseman et al. 1965). More recently, Olesen and associates (2003) found that Blumeria graminis f. sp. avenae also could grow on wheat and barley preinoculated with virulent formae speciales of Blumeria graminis. This pathosystem has provided an impres- 
sive demonstration of how defense suppression is localized to host cells that are adjacent to ones preinfected by the virulent pathogen (Lyngkjær and Carver 2000). The suppression of disease resistance may involve highly conserved host targets among these diverse host-pathogen interactions. However, given the separate phylogeny of oomycetes and fungi, the underlying parasite determinants of defense suppression are likely to be distinct among the parasite lineages. As described above, molecular identification of defense suppressor proteins from oomycetes and fungi obviously is required to resolve this hypothesis.

The gene $R A C l$ described above potentially could be used in experimental host lines to identify effector-like proteins that elicit cell death, assuming that this particular $R$ gene may confer recognition of an $A$. candida subsp. arabidopsis suppressor (see discussion above). We are progressively identifying additional $R$ genes that confer white rust resistance, which also could be used for similar experiments (Borhan et al. 2008). High-throughput assays using bombardment assays or bacterial delivery need to be devised which will enable reproducible screening of candidate oomycete effectors (Holub 2006; Rehmany et al. 2005; Rentel et al. 2008; Sohn et al. 2007).

Mutant screens of Arabidopsis thaliana for enhanced resistance to Albugo candida subsp. arabidopsis Acem1 may enable identification of candidate host proteins that are vulnerable to suppression by this parasite. Such screens have been used successfully for investigating compatibility of powdery and downy mildew parasites in Arabidopsis thaliana (Van Damme et al. 2005; Vogel et al. 2004). None of the published mutants, however, confer a measurable effect on $A$. candida subsp. arabidopsis compatibility (E. Holub, unpublished); therefore, direct screening for enhanced resistance mutants with $A$. candida subsp. arabidopsis will be important for future research.

Given the symptomology of $A$. candida infection, often including "green islands" and malformation of host tissue (Crute et al. 1994), reasonable criteria for identifying host regulators and candidate defense suppressors from $A$. candida would be evidence of interference with hormonal signaling networks, which are becoming more clearly defined, and particularly those implicated in responses mediated by levels of plant tissue auxin or cytokinin (Ferreira and Kieber 2005; Quint and Gray 2006). Thus, available hormonal signaling mutants should be used to assess the impact on compatibility with virulent and avirulent isolates of $A$. candida. This may provide useful information for verifying candidate defense suppressors by their expected correlative profile of hormonal imbalance.
Investigation of pathogen-mediated defense suppression potentially will be advanced in Arabidopsis thaliana with the premiere model oomycete $H$. parasitica (Holub 2006; Sohn et al. 2007). However, the fact that infection of the Arabidopsis thaliana $l s d l$ mutant with a virulent isolate of $H$. parasitica can readily elicit runaway cell death in seedlings suggests that this parasite may not be able to sustain active suppression of host defenses. This also seems evident from previous description of "enhanced resistance" to virulent downy mildew in Ws$l s d l$, from induction of cell death that trailed closely behind the growth of $H$. arabidopsis hypha in the mesophyll of true leaves (Dietrich et al. 1997). The striking contrast with virulent Albugo candida subsp. arabidopsis, which can sustain cell death suppression in Arabidopsis thaliana $l s d 1$, is a compelling observation that, on its own, is enough to warrant the investment in oomycete genomics beyond Phytophthora spp. and $H$. parasitica which, according to Riethmüller and associates (2002), compose a narrow lineage within the Oomycetes. Albugo candida subsp. arabidopsis and its defense suppression capability represent an important and fascinating complement for downy mildew research in Arabidopsis thaliana.

\section{MATERIALS AND METHODS}

\section{Pathogen isolates and handling.}

A summary of the fungal and oomycete isolates used in this study is provided in Table 4. Albugo candida subsp. arabidopsis isolate Acem1 was maintained and prepared for experiments as described by Dangl and associates (1992). This isolate was used for all sequential inoculation experiments on Arabidopsis thaliana; inoculum was adjusted to $1.3 \times 10^{5}$ zoosporangia $\mathrm{ml}^{-1}$. The Albugo candida race 2 isolate Bihar-SP was used for all experiments on $B$. juncea; inoculum was adjusted to $2 \times 10^{5}$ zoosporangia $\mathrm{ml}^{-1}$. The $H$. arabidopsis isolates Cala2, Cand5, Noks1, and Hiks1 were maintained and prepared for experiments in Arabidopsis thaliana as described by Tör and associates (2002); inoculum was adjusted to $7 \times 10^{4}$ spores $\mathrm{ml}^{-1}$.

$H$. parasitica isolates from their respective hosts (B. juncea, B. oleracea, B. rapa, B. napus, Eruca sativa, and C. cherii) were subcultured on 7-day-old susceptible seedlings. Sporulating cotyledons were removed and shaken in refrigerated distilled water; the spore solution then was sprayed onto 7-dayold host seedlings, which were placed in sealed propagators. Inoculated plants were placed in a growth room at $18^{\circ} \mathrm{C}$ with a 16-h photoperiod. Inoculum was adjusted to $1 \times 10^{5}$ spores $\mathrm{ml}^{-1}$

Table 4. Pathogen isolates and susceptible plant accessions used for maintaining cultures of each respective isolate

\begin{tabular}{|c|c|c|c|}
\hline Pathogen species & $\begin{array}{c}\text { Isolate } \\
\text { name }\end{array}$ & Maintenance host (susceptible accession) & Source (reference) \\
\hline \multicolumn{4}{|l|}{ Albugo candida "suppressors" } \\
\hline A. candida subsp. arabidopsis & Acem 1 & Arabidopsis thaliana (Wassilewskija, Ws-3) & E. B. Holub (Holub et al. 1995) \\
\hline A. candida race 2 & Bihar SP & Brassica juncea (oilseed mustard, PPBJ-1) & A. O. Latunde-Dada (unpublished) \\
\hline \multicolumn{4}{|l|}{ Avirulent "challengers" } \\
\hline \multirow[t]{4}{*}{ Hyaloperonospora arabidopsis } & Cala2 & Arabidopsis thaliana (Ws-eds 1 ) & E. B. Holub (Holub et al. 1994; Parker et al. 1996) \\
\hline & Cand5 & Arabidopsis thaliana (Ws-eds 1 ) & E. B. Holub (Holub et al. 1994; Parker et al. 1996) \\
\hline & Hiks 1 & Arabidopsis thaliana (Ws-edsl) & E. B. Holub (Holub et al. 1994; McDowell et al. 2000) \\
\hline & Noks 1 & Arabidopsis thaliana (Ws-edsl) & E. B. Holub (Parker et al. 1996) \\
\hline \multirow[t]{7}{*}{ H. parasitica } & IP00A & B. juncea (oilseed mustard, PPBJ-1) & N. I. Nashaat, RRes (Nashaat et al. 1998) \\
\hline & IP05 & B. juncea (oilseed mustard, PPBJ-1) & N. I. Nashaat, RRes (Nashaat et al. 1998) \\
\hline & P003 & B. napus (oilseed rape cv. Capricorn) & J. A. Lucas (Sherriff and Lucas 1990) \\
\hline & PP6 & B. oleracea (cauliflower cv. Billabong) & J. A. Lucas (Silue et al. 1996) \\
\hline & IP09 & B. rapa (turnip, RES-BR-263) & N. I. Nashaat, RRes (Nashaat et al. 1998) \\
\hline & WF & Cheiranthus cherii (wallflower cv. Fairlady) & J. A. Lucas (unpublished) \\
\hline & IP10 & Eruca sativa (rocket cv. Taramira) & N. I Nashaat, RRes (unpublished) \\
\hline Bremia lactucae & $\mathrm{BL} / 96$ & Lactuca sativa (lettuce cv. Cobham Green) & E. B. Holub (obtained from I. R. Crute; unpublished) \\
\hline Erysiphe spp. & Unnamed & Arabidopsis thaliana and Brassica oleracea & Glasshouse inhabitants at WHRI (unpublished) \\
\hline Colletotrichum higginsianum & 061 & Plate culture & S. Sreenivasaprasad, Warwick HRI (O'Connell et al. 2004) \\
\hline
\end{tabular}


for experiments. For experiments in Arabidopsis thaliana using $H$. parasitica $\mathrm{P} 005$, the downy mildew inoculum was adjusted to $7 \times 10^{4}$ spores $\mathrm{ml}^{-1}$.

Bremia lactucae BL/96 was subcultured on 7-day-old cotyledons of L. sativa L. (cv. Cobham green). Lettuce seed were sown on vermiculite soaked in a nutrient solution with $1 \%$ Rovral fungicide and placed in a $15^{\circ} \mathrm{C}$ growth room with a 12 $\mathrm{h}$ photoperiod.

Seven-day-old lettuce cotyledons were sprinkled with refrigerated distilled water; then, 14-day-old seedlings with heavy downy mildew from the previous culture were harvested and used to spread inoculum onto the wet surfaces of the new lettuce cotyledons. Inoculated lettuce cotyledons then were returned to the conditions used for seed germination. For experimentation, Bremia lactucae spores were suspended in chilled distilled water. The suspension was strained and centrifuged at 2,000 $\times$ $g$ for $5 \mathrm{~min}$; the supernatant was removed and the pellet was resuspended in refrigerated distilled water. This procedure was repeated twice and the inoculum was adjusted to $5 \times 10^{4}$ sporangia $\mathrm{ml}^{-1}$.

Powdery mildew inoculum from two different morphotypes of Erysiphe spp. was collected from leaves that occurred as natural epidemics on Arabidopsis thaliana and Brassica oleracea plants in glasshouses at Warwick-HRI. These included a morphotype similar to Erysiphe cruciferarum with short conidial chains, weakly virulent in Arabidopsis thaliana Col-0 and used for the experiment described in Table 2; and a morphotype similar to $E$. orontii with long conidial chains (Plotnikova et al. 1998), and highly virulent in Col-0 and used for the experiment shown in Figure 3. All inoculum was collected from Arabidopsis thaliana leaves. Further description of the inoculation method is described below.

The $C$. higginsianum isolate IMI 349061 (O'Connell et al. 2004) was subcultured on potato dextrose agar (PDA) at $20^{\circ} \mathrm{C}$. Conidial suspensions were prepared from 10- to 12-day-old PDA cultures; inoculum was adjusted to $1 \times 10^{5}$ spores $\mathrm{ml}^{-1}$ in sterile distilled water.

\section{Sequential infection experiments.}

For experiments in Arabidopsis thaliana, 7-day-old cotyledons were inoculated first with an approximately 5- $\mu$ l drop of Albugo candida subsp. arabidopsis Acem1 zoospore suspension using methods described by Holub and associates (1995). The inoculated seedlings were incubated for 2 days in a growth room at $15^{\circ} \mathrm{C}$ with a photoperiod of $12 \mathrm{~h}$. The avirulent downy mildew isolate was introduced by placing an approximately 5$\mu \mathrm{l}$ drop of inoculum on the same cotyledons and returning for incubation at the same growth conditions. Negative and positive controls were inoculated solely with the avirulent isolate, including resistant and susceptible (Ws-eds1) Arabidopsis thaliana.

Powdery mildew inoculations in Arabidopsis thaliana were made $48 \mathrm{~h}$ after inoculation with Albugo candida subsp. arabidopsis. Prior to powdery mildew inoculation, excess moisture was removed from cotyledons with tissue paper. Leaves covered with profuse powdery mildew sporulation were removed from infected plants, which were held over Arabidopsis thaliana seedlings while spores were brushed off the leaves with a fine paintbrush. The pots of sequentially inoculated seedlings were placed in a sealed propagator and incubated for 7 days in a $20^{\circ} \mathrm{C}$ growth room with a 10 -h photoperiod. Viability of the two Erysiphe spp. was assessed by monitoring the germination of conidia on $5 \%$ agar plates (2 dai) that were incubated in the same conditions as for experimentation (data not shown).

For tests with $C$. higginsianum, Arabidopsis thaliana seedlings were inoculated with approximately 5- $\mu$ l drops of this culture (using methods described by O'Connell and associates [2004]) 2 dai with Albugo candida subsp. arabidopsis Acem1. Inoculated plants were incubated at $20^{\circ} \mathrm{C}$ in a growth room with a 10-h photoperiod for 7 days. Infection was scored 7 days after inoculation with $C$. higginsianum, and infected seedlings were categorized into classes with an assigned score. Categories included 1 = green cotyledons and adult leaves, $2=$ green cotyledons no adult leaves, $3=$ chlorotic or necrotic cotyledons with adult leaves, $4=$ chlorotic or necrotic cotyledons and no leaves, $5=$ shriveled cotyledons or leaves but turgid, and $6=$ collapsed and macerated.

$B$. juncea line 560-1 was used for all sequential inoculation experiments on $B$. juncea. After a $24-\mathrm{h}$ incubation period following the inoculation with $A$. candida race 2 (isolate Bihar$\mathrm{SP})$, cotyledons were inoculated with an avirulent downy mildew pathogen. Positive and negative controls were included; $B$. juncea line 560-1 was inoculated solely with Bihar-SP and solely with the avirulent oomycete. Inoculated seedlings were maintained in sealed plant propagators within growth cabinets as described above.

\section{Assessing sporulation}

of sequentially inoculated cotyledons.

Sporulation of downy mildew isolates was assessed in Arabidopsis thaliana experiments 7 dai. An illuminated magnifier $(\times 2)$ was used to count the number of sporangiophores per cotyledon up to 10 , and estimating higher numbers as either medium (M, 11 to 19 sporangiophores) or heavy $(\mathrm{H}$, $\geq 20$ sporangiophores). A minimum of 20 seedlings was examined, as recommended by Mert (2001). Sporulation of the $H$. parasitica isolate P005 and the Bremia lactuca isolate BL/96 was confirmed by collecting sporangiophores from sequentially inoculated Arabidopsis thaliana and using these to inoculate the respective natural host of each isolate. Sporulation of these crop pathogens 7 days later confirmed their identity, confirming that they were not contaminants (data not shown).

Powdery mildew also was assessed using an illuminated magnifier. Sporulation was considered heavy if cotyledons had $\geq 90 \%$ coverage, medium with 40 to $89 \%$ coverage, and sparse on cotyledons with $\leq 39 \%$ coverage.

Two separate sequential inoculation experiments were performed on Brassica juncea. In the first experiment, sequentially inoculated cotyledons were excised 7 dai with the avirulent pathogen and shaken in vials with $1 \mathrm{ml}$ of sterile distilled $\mathrm{H}_{2} \mathrm{O}$. Spores were counted using a hemacytometer and spore number then was estimated per square centimeter of cotyledon. In the second sequential inoculation experiment, cotyledons were excised 7 dai with the avirulent pathogen and were mounted for microscopy, which was used to assess the number of sporangiophores in several fields of view. This figure then was used to estimate the number of sporangiophores per square centimeter of cotyledon. The number of fields of view counted for sequential inoculations on $B$. juncea with downy mildews isolated from Arabidopsis thaliana and lettuce was increased to 90 to raise the probability of finding sporangiophores.

For microscopy, sequentially infected $B$. juncea cotyledons were cleared in a $3: 1(\mathrm{vol} / \mathrm{vol})$ solution of ethanol and chloroform containing $0.15 \%$ trichloroacetic acid, stained in a $0.025 \%$ solution of cotton blue in lactophenol, and mounted on glass slides.

\section{Statistical analyses.}

Data analyses were performed using the computer package GenStat (Payne et al. 2007). For experiments on Arabidopsis thaliana, the heterogeneity of sporulation scores on sequentially inoculated cotyledons between repeated experiments was assessed. For experiments with H. parasitica P005 on Arabidop- 
sis thaliana Ws-eds1, which sporulated in the absence Albugo candida subsp. arabidopsis Acem1, sporulation scores were assessed between repeated experiments with and without $A$. candida subsp. arabidopsis Acem1. This was achieved by analyzing the contingency table of numbers of cotyledons indexed by experiment and sporulation score, using a log-linear model. Where more than one experiment had been performed, data were pooled across experiments. For each different mildew isolate and each different accession of Arabidopsis thaliana, a contingency table indexed by presence or absence of Albugo candida subsp. arabidopsis Acem1 and by whether or not sporulation was observed was analyzed, again using a loglinear model. Finally, the data for $H$. parasitica P005 on Ws$e d s l$ were reanalyzed as a contingency table indexed by the presence or absence of Acem 1 and by sporulation score. In all cases, the effects of the margins of the contingency table were fitted and the significance of the interaction of interest was assessed by comparing the residual deviance to a $\chi^{2}$ distribution on the appropriate number of degrees of freedom. For the $B$. juncea data, the significance of the differences between the levels of sporulation with and without preinfection with $A$. candida was assessed using Mann-Whitney U tests.

Mean severity scores from the $C$. higginsianum experiments were analyzed using restricted maximum likelihood (REML), weighted by the numbers of seedlings scored. REML is a generalization of analysis of variance, also suitable for unbalanced data. The significance of differences between treatments was assessed using Wald tests.

\section{ACKNOWLEDGMENTS}

We thank Colin Clay (HRI) for helpful advice and assistance with scanning electron microscopy, Jeff Dangl (University of North Carolina-Chapel Hill) for providing the Arabidopsis thaliana backcross mutant Col-lsdl, John Turner (University of East Anglia) for providing the Col-RPW8 transgenic line T-B6, Nash Nashaat for providing $B$. juncea lines and $H$. parasitica isolates used in experiments on $B$. juncea, and S. Sreenivasaprasad for assisting with the $C$. higginsianum experiments. At Warwick-HRI, A. J. Cooper was supported by a Biotechnology and Biological Sciences Research Council (BBSRC) studentship, A. Woods-Tör was supported by a Daphne Jackson fellowship, and E. B. Holub was supported by BBSRC core funding. At Rothamsted, A. O. Latunde-Dada was supported by a Lawes Trust Fellowship and BBSRC core funding.

\section{LITERATURE CITED}

Aarts, N., Metz, M., Holub, E. B., Staskawicz, B. J., Daniels, M. J., and Parker, J. E. 1998. Different requirements for EDS1 and NDR1 by disease resistance genes define at least two $R$ gene-mediated signaling pathways in Arabidopsis thaliana. Proc. Natl. Acad. Sci. U.S.A. 95:10306-10311.

Austin, M. J., Muskett, P., Kahn, K., Feys, B. J., Jones, J. D., and Parker, J. E. 2002. Regulatory role of SGT1 in early $R$ gene-mediated plant defenses. Science 295:2023-2033.

Bains, S. S., and Jhooty, J. S. 1979. Mixed infections by Albugo candida and Peronospora parasitica on Brassica juncea and their control. Indian Phytopathol. 32:268-71.

Bains, S. S., and Jhooty, J. S. 1985. Association of Peronospora parasitica with Albugo candida on Brassica juncea leaves. Phytopathol. Z. 112:28-31.

Borhan, M. H., Brose, E., Beynon, J. L., and Holub, E. B. 2001. White rust (Albugo candida) resistance loci on three Arabidopsis chromosomes are closely linked to downy mildew (Peronospora parasitica) resistance loci. Mol. Plant Pathol. 2:87-95.

Borhan, M. H., Holub, E. B., Beynon, J. L., Rozwadowski, K., and Rimmer, S. R. 2004. The Arabidopsis TIR-NB-LRR gene RAC1 confers resistance to Albugo candida (white rust) and is dependent on EDS1 but not PAD4. Mol. Plant-Microbe Interact. 17:711-719.

Borhan, M. H., Gunn, N., Cooper, A., Gulden, S., Tör, M., Rimmer, S. R., and Holub, E. B. WRR4 encodes a TIR-NB-LRR protein that confers broad spectrum white rust resistance in Arabidopsis thaliana to four physiological races of Albugo candida. Mol. Plant-Microbe Interact. $21: 757-768$
Botella, M. A., Parker, J. E., Frost, L. N., Bittner-Eddy, P. D., Beynon, J. L., Holub, E. B., and Jones, J. D. G. 1998. Three genes of the Arabidopsis RPP1 complex locus recognize distinct Peronospora parasitica (downy mildew) avirulence determinants. Plant Cell 10:18471860.

Century, K., Shapiro, A. D., Repetti, P. P., Dahlbeck, D., Holub, E. B., and Staskawicz, B. J. 1997. NDR1, a pathogen induced component required for Arabidopsis disease resistance. Science 278:1963-1965.

Chaurasia, S. N. P., Singh, U. P., and Singh, H. B. 1982. Preferential parasitism of Peronospora parasitica on galls of Brassica campestris caused by Albugo cruciferarum. Trans. Br. Mycol. Soc. 78:379-381.

Constantinescu, O., and Fatehi, J. 2002. Peronospora-like fungi (Chromista, Peronosporales) parasitic on Brassicaceae and related hosts. Nova Hedwigia 74:291-338.

Crute, I., Beynon, J., Dangl, J., Holub, E., Mauch-Mani, B., Slusarenko, A., Staskawicz, B., and Ausubel, F. 1994. Microbial pathogenesis of Arabidopsis. Pages 705-747 in: Arabidopsis. Monograph 27. E. M Meyerowitz and C. R. Somerville, eds. Cold Spring Harbor Laboratory Press, Cold Spring Harbor, NY, U.S.A.

Dangl, J. L., Holub, E. B., Debener, T., Lehnackers, H., Ritter, C., and Crute, I. 1992. Genetic definition of loci involved in Arabidopsispathogen interactions. In: Methods in Arabidopsis Research. C. Koncz, N.-H. Chua, and J. Schell, eds. World Scientific, Singapore.

deWit, P. J. G. M. 2007. How plants recognize pathogens and defend themselves. Cell. Mol. Life Sci. 64:2726-2732.

Dietrich, R. A., Richberg, M. H., Schmidt, R., Dean, C., and Dangl, J. L. 1997. A novel zinc finger protein is encoded by the Arabidopsis LSDI gene and functions as a negative regulator of plant cell death. Cell 88:685-94.

Ellingboe, A. H. 1976. Genetics of host-parasite interactions. Pages 761778 in: Physiological Plant Pathology, Encyclopedia of Plant Physiology. New Ser. Vol. 4. R. Heitefuss and P. H. Williams, eds. Springer Verlag, New York.

Eulgem, T., Weigman, V. J., Chang, H. S., McDowell, J. M., Holub, E. B., Glazebrook, J., Zhu, T., and Dangl, J. L. 2004. Three genetically separable $R$ gene-signaling pathways converge to regulate a largely overlapping transcriptome. Plant Physiol. 135:1129-1144.

Ferreira, F. J., and Kieber, J. J. 2005. Cytokinin signaling. Curr. Opin. Plant Biol. 8:518-525.

Gill, C. C. 1965. Increased multiplication of viruses in rusted bean and sunflower tissue. Phytopathology 55:141-147.

Goker, M., Riethmüller, A., Voglmayr, H., Weiss, M., and Oberwinkler, F. 2004. Phylogeny of Hyaloperonospora based on nuclear ribosomal internal transcribed spacer sequences. Mycol. Progr. 3:83-94.

Heath, M. C. 1980. Effects of infection by compatible species or injection of tissue extracts on the susceptibility of nonhost plants to rust fungi. Phytopathology 70:356-360.

Holub, E. B. 2001. The arms race is ancient history in Arabidopsis, the wildflower. Nat. Rev. Genet. 2:516-527.

Holub, E. B. 2006. Evolution of parasitic symbioses between plants and filamentous microorganisms. Curr. Opin. Plant Biol. 9:397-405.

Holub, E. B. 2007. Natural variation in innate immunity of a pioneer species. Curr. Opin. Plant Biol. 10:415-424.

Holub, E. B. Natural history of Arabidopsis thaliana and oomycete symbioses. Eur. J. Plant Pathol. In press.

Holub, E. B., and Beynon, J. L. 1997. Symbiology of mouse-ear cress (Arabidopsis thaliana) and oomycetes. Adv. Bot. Res. 24:227-273.

Holub, E. B., and Cooper, A. 2004. The Matrix, reinvention in plants: how genetics is unveiling secrets from non-host disease resistance. Trends Plant Sci. 9:211-214.

Holub, E., Brose, E., Beynon, J., and Crute, I. 1993. Identification and mapping of loci in A. thaliana for resistance to downy mildew and white blister. Pages 21-35 in: Arabidopsis as a Model System for Studying Plant-Pathogen Interactions. K. Davis and R. Hammerschmidt, eds. American Phytopathological Press, St. Paul, MN, U.S.A.

Holub, E. B., Beynon, J. L., and Crute, I. R. 1994. Phenotypic and genotypic characterization of interactions between isolates of Peronospora parasitica and accessions of Arabidopsis thaliana. Mol. Plant-Microbe Interact. 7:223-239.

Holub, E. B., Brose, E., Tör, M., Clay, C., Crute, I. R., and Beynon, J. L. 1995. Phenotypic and genotypic variation in the interaction between Arabidopsis thaliana and Albugo candida. Mol. Plant Microbe-Interact. 8:916-928.

Kamoun, S. 2006. A catalogue of the effector secretome of plant pathogenic oomycetes. Annu. Rev. Phytopathol. 44:41-60.

Lipka, V., Dittgen, J., Bednarek, P., Bhat, R., Wiermer, M., Stein, M., Landtag, J., Brandt, W., Rosahl, S., Scheel, D., Llorente, F., Molina, A., Parker, J., Somerville, S., and Schulze-Lefert, P. 2005. Pre- and postinvasion defenses both contribute to nonhost resistance in Arabidopsis. Science 310:1180-1183. 
Lyngkjær M. F., and Carver T. L. W. 2000. Conditioning of cellular defense responses to powdery mildew in cereal leaves by prior attack. Mol. Plant Pathol. 1:41-49.

McDowell, J. M., Cuzick, A., Can, C., Beynon, J. L., Dangl, J. D., and Holub, E. B. 2000. Downy mildew (Peronospora parasitica) resistance genes in Arabidopsis vary in functional requirements for NDR1, EDS1, NPR1, and salicylic acid accumulation. Plant J. 22:523-529.

Mert, F. 2001. Quantification of enhanced downy mildew susceptibility and camalexin accumulation in Arabidopsis thaliana. Ph.D. dissertation, Imperial College of Biotechnology, Science and Medicine at Wye, University of London, London.

Moseman, J.,G., and Greeley, L. W. 1964. Predisposition of wheat by Erysiphe graminis f. sp. tritici to infection with Erysiphe graminis f. sp. hordei. Phytopathology 54:618

Moseman, J. G., Scharen, A. L., and Greeley, L. W. 1965. Propagation of Erysiphe graminis f. sp. tritici on barley and E. graminis f. sp. hordei on wheat. Phytopathology 55:92-96.

Nashaat, N. I., Heran, A., and Kolte, S. J. 1998. New differential responses and genes for resistance to Peronospora parasitica in Brassica juncea. In: Abstracts of Invited and Offered Papers, 7th Int. Congr. Plant Pathol ICPP98 Pap. No. 3.4.68. Edinburgh.

O'Connell, R., Herbert, C., Sreenivasaprasad, S., Khatib, M. EsquerréTugayé, M., and Dumas, B. 2004. A novel Arabidopsis thaliana-Colletotrichum pathosystem for the molecular dissection of plant-fungus interactions. Mol. Plant-Microbe Interact. 17:272-282.

Olesen, K. L., Carver, T. L. W., and Lyngkjær, M. F. 2003. Fungal suppression of resistance against inappropriate Blumeria graminis formae speciales in barley, oat and wheat. Physiol. Mol. Plant Pathol. 62:37-50.

Ouchi, S., and Oku, H. 1981. Susceptibility as a process induced by pathogens. Pages 33-44 in: Plant Disease Control. R. C. Staples and G. H. Toenniessen, eds. Wiley Press, New York.

Parker, J. E., Holub, E. B., Frost, L. N., Falk, A., Gunn, N. D., and Daniels, M. J. 1996. Characterization of eds 1, a mutation in Arabidopsis suppressing resistance to Peronospora parasitica specified by several different RPP genes. Plant Cell 8:2033-2046.

Payne, R. W., Harding, S. A., Murray, D. A., Soutar, D. M., Baird, D. B. Welham, S. J., Kane, A. F., Gilmour, A. R., Thompson, R., Webster, R., and Tunnicliffe Wilson, G. 2007. GenStat Release 10; Part 2, Statistics. VSN International, Hemel Hempstead, U.K.

Plotnikova J. M., Reuber T. L., and Ausubel F. M. 1998. Powdery mildew pathogenesis of Arabidopsis thaliana. Mycologia 90:1009-1016.

Quint, M., and Gray, W. M. 2006. Auxin. Curr. Opin. Plant Biol. 9:448453

Rehmany, A. P., Lynn, J. R., Tör, M., Holub, E. B., and Beynon, J. L. 2000. A comparison of Peronospora parasitica (downy mildew) isolates from Arabidopsis thaliana and Brassica oleracea using amplified fragment length polymorphism and internal transcribed spacer 1 sequence analyses. Fungal Gen. Biol. 30:95-103.

Rehmany, A. P., Gordon, A., Rose, L. E., Allen, R. L., Armstrong, M. R., Whisson, S. C., Kamoun, S., Tyler, B. M., Birch, P. R. J., and Beynon, J. L. 2005. Differential recognition of highly divergent downy mildew avirulence gene alleles by $R P P 1$ resistance genes from two Arabidopsis lines. Plant Cell 17:1839-1850.

Rentel, M. C., Leonelli, L., Dahlbeck, D., Zhao, B., and Staskawicz, B. J. 2008. Recognition of the Hyaloperonospora parasitica effector ATR13 triggers resistance against oomycete, viral and bacterial pathogens. Proc. Natl. Acad. Sci. U.S.A. 105:1091-1096.

Riethmüller, A., Voglmayer, H., Göker, M., Weiß, M., and Oberwinkler, F. 2002. Phylogenetic relationships of the downy mildew (Peronosporales) and related groups based on nuclear large subunit ribosomal DNA sequences. Mycologia 94:834-849.

Rimmer, S. R., Mathur, S., and Wu, C. R. 2000. Virulence of isolates $\mathrm{Al}$ bugo candida from western Canada to Brassica species. Can. J. Plant
Pathol. 22:229-35.

Sansome, E., and Sansome, F. W. 1974. Cytology and life history of Peronospora parasitica on Capsella bursa-pastoris and of Albugo candida on C. bursa-pastoris and Lunaria annua. Trans. Br. Mycol. Soc. 62:323-332.

Sherriff. C., and Lucas, J. A. 1990. The host range of downy mildew Peronospora parasitica (Pers. Ex Fr.) Fr. from Brassica crop species. Plant Pathol. 39:77-91.

Silue, D., Nashaat, N. I., and Tirilly, Y. 1996. Differential responses of Brassica oleracea and B. rapa accessions to seven isolates of Peronospora parasitica at the cotyledon stage. Plant Dis. 80:142-144.

Sinapidou, E., Williams, K., Nott, L., Bahkt, S., Tör, M., Crute, I. R., Bittner-Eddy, P. D., and Beynon J. L. 2004. Two TIR:NB:LRR genes are required to specify resistance to Peronospora parasitica isolate Cala2 in Arabidopsis. Plant J. 38:898-909.

Singh, U. S., Nashaat, N. I., Doughty, K. J., and Awasthi, R. P. 2002. Altered phenotypic response to Peronospora parasitica in Brassica juncea following prior inoculation with an avirulent or virulent isolate of $\mathrm{Al}$ bugo candida. Eur. J. Plant Pathol. 108:555-564.

Sogin, M. L., and Silberman, J. D. 1998. Evolution of the protests and protistan parasites from the perspective of molecular systematics. Int. J. Parasitol. 28:11-20.

Sohn, K. H., Lei, R., Nemri, A., and Jones, J. D. 2007. The downy mildew effector proteins ATR1 and ATR13 promote disease susceptibility in Arabidopsis thaliana. Plant Cell 19:4077-4090.

Staskawicz, B. J., Ausubel, F. M., Baker, B. J., Ellis, J. G., and Jones, J. D. G. 1995. Molecular genetics of plant disease resistance. Science 268:661-667.

Tör, M., Gordon, P., Cuzick, A., Eulgem, T., Sinapidou, E., Mert-Türk, F., Can, C., Dangl, J. L., and Holub, E. B. 2002. Arabidopsis SGT1b is required for defense signaling conferred by several downy mildew resistance genes. Plant Cell 14:993-1003.

Tör, M., Yemm, A., and Holub, E. B. 2003. The role of proteolysis in $R-$ gene mediated defense in plants. Mol. Plant Pathol. 4:287-296.

Van Damme, M., Andel, A., Huibers, R. P., Panstruga, R., Weisbeek, P. J., and Van den Ackerveken, G. 2005. Identification of Arabidopsis loci required for susceptibility to the downy mildew pathogen Hyaloperonospora parasitica. Mol. Plant-Microbe Interact. 18:583-592.

Vogel, J. P., Raab, T. K., Somerville, C. R., and Somerville, S. C. 2004 Mutations in $P M R 5$ result in powdery mildew resistance and altered cell wall composition. Plant J. 40:968-978.

Webster, J. 1980. Introduction to Fungi. Cambridge University Press, New York.

Whisson, S. C., Boevink, P. C., Moleleki, L., Avrova, A. O., Morales, J. G., Gilroy, E. M., Armstrong, M. R., Grouffaud, S., van West, P., Chapman, S., Hein, I., Toth, I. K., Pritchard, L., and Birch, P. R. 2007. A translocation signal for delivery of oomycete effector proteins into host plant cells. Nature 450:115-118.

Win, J., Morgan, W., Bos, J., Krasileva, K. V., Cano, L. M., ChaparroGarcia, A., Ammar, R., Staskawicz, B. J., and Kamoun, S. 2007. Adaptive evolution has targeted the C-terminal domain of the RxLR effectors of plant pathogenic oomycetes. Plant Cell 19:2349-2369.

Xiao, S., Elwood, S., Calis, O., Patrick, E., Li, T., Coleman, M., and Turner, J. G. 2001. Broad-spectrum mildew resistance in Arabidopsis mediated by $R P W 8$. Science 291:118-120.

Yarwood, C. E. 1951. Associations of rust and virus infections. Science 114:127-128.

Yarwood, C. E. 1977. Pseudoperonospora cubensis in rust infected bean. Phytopathology 67:1021-1022.

Yun, B. W., Atkinson, H. A., Gaborit, C., Greenland, A., Read, N. D. Pallas, J. A., and Loake, G. 2003. Loss of actin cytoskeletal function and EDS1 activity, in combination, severely compromises non-host resistance in Arabidopsis against wheat powdery mildew. Plant J. 34:768-777. 